\title{
A Discussion of the Realistic Significance and Paths of Rural Revitalization Promoted by Soul-Nurturing Culture
}

\author{
Kang Zhao ${ }^{1, a^{*}}$ Long Dan ${ }^{1, b}$ Deng Ting ${ }^{2, c}$ \\ ${ }^{I}$ School of Education, China West Normal University, Nanchong, Sichuan,China \\ ${ }^{2}$ No.1 Middle School of Jiangling , Nanchong, Sichuan,China \\ a*kangzhao168@126.com \\ b1969085353@qq.com \\ 664991816@qq.com
}

\begin{abstract}
Soul-nurturing culture is not only an important task of the current Chinese ideological construction, but also a functional manifestation of social practice activities carried by culture itself. The function of soul-nurturing and people-cultivating of culture itself has promoted cultural revitalization to become an important component of the rural revitalization strategy. It is necessary to deeply comprehend the due meaning of rural revitalization promoted by soul-nurturing culture, vigorously promote the excellent Chinese traditional culture and advanced socialist culture to nurture the soul of the rural people, emphasize the scientific guidance of core values, strengthen the cultural self-confidence and identity of the rural people, actively carry out cultural inheritance and innovation, and provide spiritual power for sustainable development for rural revitalization.
\end{abstract}

Keywords: Soul-nurturing culture, Rural revitalization, cultural self-confidence, Cultural identity, Cultural innovation

\section{文化铸魂助力乡村振兴的现实意蕴与路径探讨}

\author{
康钊 $1, a^{*}$ 龙丹1, b 邓婷2,c \\ ${ }^{1}$ 西华师范大学教育学院 心理健康教育研究中心 南充四川中国 \\ 2 四川省南充市嘉陵第一中学 南充四川中国 \\ a*kangzhao168@126.com \\ b1969085353@qq.com \\ c664991816@qq.com
}

\section{中文摘要}

文化铸魂既是当前中华民族意识形态建设的重要任务, 也是文化本身承载的社会实践活动的功能体现。文化本 身所具有的铸魂育人功能促成文化振兴成为乡村振兴战略的重要组成。深刻领会文化铸魂助力乡村振兴的应有 之义，大力弘扬中华民族优秀传统文化和社会主义先进文化对乡村民众进行文化铸魂，强调以核心价值观为科 学引领, 强化乡村民众主体的文化自信与文化认同, 积极进行文化传承与创新, 为乡村振兴提供持续发展的精 神动力。

关键词：文化铸魂，乡村振兴，文化自信，文化认同，文化创新 


\section{1. 引言}

乡村要振兴, 文化应先行。正因为文化能够有效 调动和凝聚乡村振兴的各方力量, 文化振兴应当而且 必然成为中华民族乡村振兴的铸魂工程。同时, 文化 能以其先导特性和战略特性为乡村振兴战略提供必 要的精神鼓励、智力支持与道德浸润, 由此成为国家 和民族保持长期稳定发展的核心灵魂, 亦是谋求中华 民族科学发展的更为基本、更显深沉、更加持久的力 量源泉。文化铸魂既是当前中华民族社会意识形态领 域建设的重要任务, 同时也应是文化本身所承载的社 会实践活动的功能体现。积极探索新的历史时期文化 铸魂助力乡村振兴的意蕴及其实现路径, 能够为乡村 振兴提供持续发展的精神动力, 助推乡村振兴战略目 标早日实现。

\section{2. 文化铸魂助力乡村振兴的现实意蕴解读}

\section{1. 文化铸魂是乡村振兴战略的重要组成}

文化是中华民族得以繁荣昌盛与强心固本的精 神纽带, 支撑着中华民族积极谋求科学发展的理想信 念、承载着中华民族数千年来自强不息的集体记忆、 塑造着中华民族特立独行的精神风貌。中华民族乡村 的振兴发展自然离不开文化的振兴与发展。乡村文化 是指在以乡村民众为活动主体, 在长期的劳动生产过 程中所形成的具有独特的乡土人文气息的各种物质 财富和精神财富的总和。乡村文化的振兴发展是当前 全面实现乡村经济的可持续发展, 以及促进乡村产业 兴旺与乡村民众生活富裕的重要动力源泉，也是促进 乡村真正实现乡风文明和宜居生态环境建设的有效 支撑力量。乡村振兴过程中既要重视塑造乡村之形, 建设天蓝、水绿、山青之乡村, 更要重视铸造乡村之 魂, 建设富裕、文明、和谐之乡村。为全面贯彻落实 习近平总书记的重要指示, 实践中我们应当重视挖掘 和提升乡村的文化价值并对其进行创造性转化与创 新性发展, 通过文化塑造和深刻影响乡村民众的主体 发展意识, 着力培育适应新农村建设与发展需求的文 明乡风、良好家风与淳朴民风，大力改善乡村民众的 整体精神风貌，全面提升乡村民众群体的文化层次与 文明程度, 焕发乡村现代文明新气象, 为乡村振兴提 供持续发展的精神动力。宋小霞等 (2019) 认为文化 振兴是当前我国全面实施乡村振兴的固本之道, 要教 育乡村民众尊重理解与认同乡土文化, 文化振兴是乡 村振兴的铸魂工程与重要保障, 文化振兴应当成为乡 村振兴的应有之义[1]。

\section{2. 文化铸魂助力乡村振兴的现实意蕴}

个体作为文化存在的充分依托和真实体现, 文化 铸魂离不开对中华民族优秀传统文化、革命文化和社 会主义先进文化的高度认同, 同时, 还应当包括对这 些文化的创新发展, 以及由此而产生的文化自信[2]。 中华民族优秀传统文化是保证中华民族自身不断发 展壮大的强大基因，同时也是中华民族文化传承延续 的核心血脉和中华民族自强不息的精神命脉所在, 因
而它能够极大彰显和增强中华民族对自身文化的自 信心与自豪感 [3]。从本质上说, 文化铸魂应当是中华 儿女积极进行文化探寻、文化创造与文化构建的社会 实践活动, 这种实践活动既是中华民族文化知识和集 体智慧的不断积累，同时也是中华民族在新历史时期 更深层次的价值与精神追求。文化铸魂不仅在当前我 国全面建设中国特色社会主义历史时期提升中华民 族的整体文化实力发展战略中居于核心地位，同时也 是新时期中华民族文化发展战略的重要组成乃至核 心内容[4]。

\subsection{1. 核心价值观：乡村文化铸魂的整体统筹}

社会主义核心价值观作为文化的核心灵魂所在， 沉淀着中华民族数千年发展过程中累积下来的理想 信念、民族精神和伦理道德，自然在极大程度上影响 和决定着我国当前文化发展的基本性质和发展走向。 中华民族核心价值观体系蕴含着极强的生命力、凝聚 力和感召力, 能够充分体现出中华民族深厚的文化底 蕴和坚强实力。社会主义核心价值观是中华民族优秀 传统文化、革命文化与社会主义先进文化的核心凝聚 和极其精确的概括表达，是中华民族发展壮大的兴国 之魂, 也是文化铸魂全面实施的整体统筹。当前我们 在全力推进与实施文化铸魂助力乡村振兴发展这一 宏伟战略，必须坚持用社会主义核心价值观来引领乡 村民众凝魂聚力, 借助文化铸魂育人来形成并构筑极 具特色的中国精神、中国价值和中国力量，借此进一 步增强中华民族文化的凝聚力、吸引力与影响力 [5]。 在乡村振兴过程中，我们应当切实把全力进行社会主 义建设并最终实现共产主义的理想信念和社会主义 核心价值观作为文化铸魂的核心内容，全面贯穿于乡 村民众的日常生活和文化建设的各个方面，全力推进 社会主义核心价值观的生活化与制度化，积极营造良 好的文化场域氛围和社会生态环境，将社会主义核心 价值观真正融入乡村民众的生活世界，内化为具体的 价值标准和行动准则, 有效促进和谐社会建设。同时, 要借助各种丰富多彩、生动活泼的文化载体和宣传教 育活动, 积极拓展和创新运用弘扬社会主义价值观的 新思路, 不断探索乡村振兴文化铸魂的具体路径与方 法, 通过教育引导、舆论宣传、文艺熏陶等多种方式, 强化对乡村民众的理想信念和核心价值观教育引领， 坚定乡村民众的理想信念和精神追求，真正实现铸牢 民族之魂。

\subsection{2. 文化自信: 乡村文化铸魂的坚实基础}

所谓文化自信，是指一个国家或民族对自身所主 导和拥有的文化思想内核及其社会价值的充分肯定, 也是对自身文化独具的品质特征与旺盛生命力的高 度体认，更是对自身文化未来不断获得新的发展所持 有的坚定信念。坚持文化自信就是要对中华民族优秀 传统文化、革命文化和社会主义先进文化保持高度的 主体认同与内在自信，对自身文化的价值呈现及其拥 有的生命力保持坚定不移的信心和不断追求更好发 展的希望。习近平总书记曾明确指出: 社会主义现代 化建设实践中我们应当保持三个方面的自信, 即要坚 定中国特色社会主义道路自信、理论自信和制度自信, 而这三个自信归根结底就是要坚定我们的文化自信, 
因为文化自信是社会主义建设过程中更为基本、更加 深沉、更能持久的发展力量[6]。中华民族优秀传统文 化是我们坚定文化自信的历史根基，其中蕴藏着十分 丰富的哲学思想、人文精神和道德理念，文化自信就 是反对历史虚无主义和文化虚无主义，对中华民族文 化发展历史能够积极接纳和认可, 并因此具有强烈而 深沉的民族自豪感。文化自信同样也来源于当代中国 革命与改革开放所取得的伟大成就, 因此我们要筑牢 这一精神支柱，对中国革命历史要有充分的肯定，对 新中国发展历程要有充分的肯定, 坚定传承与发展中 国革命文化的信心和决心。我们还应当知道, 社会主 义先进文化是马克思主义中国化的最新成果体现, 是 民族的、科学的、大众的文化, 是有极强生命力、凝 聚力和感召力的文化, 要真正实现中华民族对自身未 来发展的全方位把控, 我们必须重视传承、保护和大 力建设发展社会主义先进文化。与此同时, 我们还应 当重视加强乡土文化的发展建设力度, 树立对于中华 民族乡土文化的全面自信。因为乡土文化本身就是中 华民族优秀传统文化的坚实根基所在, 同时也是坚定 中华民族文化自信的强力依托。乡土文化自信源自于 对乡土文化的高度自觉与主体内在自醒, 是基于对乡 土文化价值的深刻认识而形成的积极认同, 自然应当 是乡村文化振兴与发展的重要组成。

\subsection{3. 文化认同: 乡村文化铸魂的支撑源泉}

人类社会发展的历史既是社会文化得以不断传 承的历史, 同时也是社会文化得到发展和创新的历史。 人类社会不断传承和发展创新生成的文化实际上就 是人类在其社会历史活动过程中所创造出来的一切 物质财富和精神财富的总和。社会文化水平不仅能够 较大程度地反映社会的经济政治基本特征, 同时也是 民族共同体意识的重要支撑，而民族共同体最直接的 体现就是对文化的高度认同。文化认同是个体被群体 文化所影响而产生的主体感觉或价值判断, 是指个体 对于自己所置身于其中的文化的接纳认可以及所属 的文化群体的积极内化, 由此产生相应的文化归属感 并获得、保持与创新相关文化价值的社会心理活动。 具体说来, 文化认同包括对社会文化的价值规范的高 度认同、对民族信仰与风俗习惯的积极认同、对不同 语言文化与艺术品格的接纳认同等方面。文化认同的 实质其实就是对中国特色社会主义文化的高度认同, 也是个体不断获得文化群体归属感的具体途径和生 成过程。相对于个体自身的成长发展而言, 文化认同 能够深刻体现和影响着个体的社会身份认同与自我 认同; 从社会发展角度而言, 文化认同表现为主体要 以中华民族文化为社会发展的核心凝聚力, 同时应当 学会对多元文化交流体系中的文化群体进行明确辨 识与科学整合。新的历史时期我们所认同的主流文化 应当是历久弥新的优秀传统文化、激昂向上的革命文 化与生机勃勃的社会主义先进文化的深度融合。文化 认同是中华儿女对中华民族文化体系的思想情感、理 性认知与价值信仰的重要支撑, 也是铸牢中华民族核 心灵魂和主体意识的源头活水。

\subsection{4. 文化创新：乡村文化铸魂的发展动因}

注重文化的创新是文化得以不断发展的实质所 在, 文化创新的功能实现也必然应当在多种文化的交 流与碰撞中发生。文化创新是把中华民族优秀传统文 化与现实文化二者有机统一起来, 在多元文化的交融 和互动之中加以改造与发展。传统文化是社会历史发 展进程中文化灵魂和精神家园的深刻积淀, 能够为现 代文化的发展提供丰富的滋养资源。习近平总书记多 次强调要重视充分实现中华民族优秀传统文化的创 造性转化和创新性发展, 要求我们在社会主义现代化 建设实践过程中要善于把弘扬中华民族优秀传统文 化和发展现实文化真正协调和统一起来, 在继承中发 展, 在发展中继承。深入挖掘中华民族传统文化的优 秀基因, 注重充分发挥传统文化所具有的物质文化和 制度文化所无法比拟的价值整合功能以及精神聚合 作用。我们所倡导的文化铸魂就是要用融涵中华民族 传统文化精神和时代精神而形成的当代中国精神，去 铸造和培育当代国人更具中国特色、中国风格和中国 气派的“中国魂”[7]。中国文化要真正走向世界, 必须 最大程度地充分吸取西方文化体系中的积极因子，同 时也要坚守和传承中华民族传统文化的精华, 将二者 有机结合起来。做到既要敢于将优秀的外来文化全面 引进来, 也要勇于让中华文化真正走出去, 理性看待 中西方不同文化之间的冲突与融合, 全面深化对世界 文化认知的深度和广度。我们所强调的文化铸魂就是 要培育能够全面认识中国历史与现实、认清世界局势、 具有创新精神和广阔国际视野的时代新人。

\section{3. 文化铸魂助力乡村振兴的路径探讨}

注重乡村文化建设是新时代中国乡村振兴发展 战略的重要组成, 是新农村发展的坚实根基和动力源 泉，也是丰富乡村民众文化生活的精神食粮。谢茹 （2020）指出应当重视重塑乡村文化新内涵，再造乡 村文化新业态, 聚合乡村文化新动力, 借助文化铸魂 促进乡村振兴发展 [8]。当前, 我国社会主义现代化建 设已经进入全新的发展时期, 我们必须高度重视乡村 文化建设工作, 积极探讨文化铸魂助力乡村振兴的有 效路径, 全力助推乡村振兴战略目标早日达成。

\section{1. 弘扬中华民族优秀传统文化，厚植乡村文 化根脉}

文化是一个国家和民族得以不断发展壮大的核 心灵魂, 文化的繁荣兴盛事关中华民族的复兴伟业, 我们必须在大力弘扬中华民族优秀传统文化的同时, 积极推进乡村文化建设力度，厚植乡村文化根脉，科 学助力乡村振兴。乡村是中华民族传统文化特别是乡 土文化和民俗文化的重要来源和栖身场所, 乡村文化 是世代乡村民众在长期的生产生活实践过程中积累 下来的文化实践经验与集体智慧的宝贵结晶, 乡村所 独有的地形地貌、风土人情与村落建设等都可能构成 极其丰富的乡村传统文化资源。可以说，中华民族文 化的核心根脉就在乡村, 要想更好地传承和保护中华 民族的传统文化, 就必须更好地守住乡村文化这一根 脉, 毕竟乡村文化同样承载着中华文化厚重的价值取 
向、基本品性和审美情趣等文化内涵。社会各界要充 分重视发挥乡村文化的积极引领作用, 积极唤醒乡村 民众的参与热情, 全面调动沉睡的乡村文化资源, 大 力传承与弘扬乡土文化, 充分发掘地方历史文化与特 色文化资源, 让乡村文化在乡村振兴过程中真正发挥 出文化铸魂的积极功用。

\section{2. 加强乡村文化教育与宣传力度, 畅通乡村 文化流通渠道}

乡村文化振兴实践中我们应当重视加强针对乡 村民众的文化教育和宣传活动, 因为要真正全面实现 乡村的文化振兴，乡村民众文化素质的提高至关重要。 要重视激发和调动乡村民众参与乡村文化建设的积 极性, 鼓励乡村民众认真学习和接收先进文化思想, 加强对乡村民众的文化知识教育、革命传统教育和法 制法纪教育, 提高乡村民众的文化素养水平，提高乡 村民众参与乡村文化建设的基本能力。同时，结合当 前现代新型媒体技术的发展大力加强针对乡村民众 的网络信息技术教育，促成乡村民众掌握现代信息技 术与应用技能, 不断创新乡村文化的传播模式。同时, 乡村文化的生命力在于广泛传播和大力弘扬, 在全面 传承弘扬中华民族传统文化的同时, 还要努力让乡村 本土优秀文化真正走出去, 也要让外地乡村特色文化 引进来。要在乡村振兴过程中畅通主流文化、本土文 化与传统文化的传播渠道, 让文化全面发挥出沟通、 交流和凝聚的积极作用, 促进乡村基层真正实现民主 自治, 与此同时, 全面加强乡村法治与德治建设力度, 促进乡村治理科学体系的真正形成。

\section{3. 培育乡村文化自信，激发乡村民众主体发 展内生动力}

乡村文化是乡村社会发展历史给我们留下的美 好回忆和厚重情怀, 是孕育和生成现代文明的文化摇 篮。同时, 乡村文化是全面提升乡村民众日常生活质 量的重要精神食粮, 是新的历史时期我国乡村振兴与 发展的坚实根基和动力源泉。加强乡村民众的文化自 信, 就是要让乡村民众真正提高对乡土文化积极价值 的科学体认, 并能理性客观地看待乡土文化的乡村振 兴功能。乡村文化是在不断适应乡村民众生活的基础 上得以发展和传承的, 必须大力促进乡村民众对乡村 文化本身具有积极的接纳和认同感。乡村振兴实践中 应当重视帮助广大乡村民众认真梳理乡村文化建设 中可能遭遇的各种问题与挑战, 充分调动乡村民众积 极参与乡村文化建设工作，促使乡村民众形成主体发 展的内生动力和使命担当。要大力发展乡贤文化, 科 学引领乡村民众学会见贤思齐与崇德向善, 激发乡村 民众热爱家乡与心系发展的乡土情结, 促成其转化为 乡村振兴的强大动力。此外, 我们要重视对乡村文化 体系进行系统挖掘与全面重塑, 能够让乡村民众充分 感受到新时期的各种新气象, 全面激发乡村振兴中的 文化活力, 不断拓展乡村文化发展空间, 助推乡村民 众更好地接纳乡村文化并以此彰显中华民族的文化 自信, 使乡村文化在当前多元文化交融的发展格局中 充分体现其自身独有的文化特色因子, 借此充分实现 文化助力乡村振兴的铸魂功能。

\section{4. 发挥乡愁乡情纽带作用, 创造乡村文化发 展新态势}

当前社会经济的高速发展无法同时也不应当阻 断乡土文化的根基, 乡村社会不能变成荒芜的家园和 留守的空间, 更不能成为我们记忆的故园。文化铸魂 助力乡村振兴要以乡愁乡情为纽带, 吸引各类优秀人 才回乡反哺, 调动乡村民众参与乡村建设的主动性和 积极性, 让乡愁乡情情结注入家乡的发展规划之中。 同时, 要创新文化发展模式, 统筹乡村文化发展规划, 立足乡村文化特色和建设实际, 将乡村文化建设与地 方旅游经济、生态发展等高度融合, 推动当前的乡村 建设工作实现全面转型或完美升级, 全力实现乡村文 化的多元融合发展。事实上, 结合我国乡村发展的现 实实际，任何乡村的发展历史、文物古迹以及民间技 艺等都可以作为乡村文化生活具体开展的核心要素, 我们可将地方经济发展与文化产业建设和文化遗产 传承等项目有效结合, 大力弘扬与传承地方传统文化 项目, 在积极推进乡村文化全面输出的同时带动当地 的经济与社会发展, 全面提升乡村文化经济创造力和 文化生产力, 推动乡村文化振兴与生态振兴、产业振 兴融合发展, 创造乡村振兴发展新态势。

\section{4. 结论}

正是因为文化本身所具有的铸魂育人功能, 由此 促成文化振兴成为乡村振兴战略的重要组成。文化振 兴既能为乡村的全面振兴与发展提供丰富的滋养哺 育和源泉支撑, 同时也是乡村振兴的坚强根脉与核心 灵魂。我们应当重视全面激活唤醒与开发利用乡村既 有的和潜在的各种文化资源, 真正通过乡村文化铸魂 助推乡村振兴战略目标的早日实现。

\section{致谢}

本文为西华师范大学基本科研业务费项目《西部 地区乡村振兴的文化铸魂研究: 中国传统文化与西方 心理学整合视角》（19B003）、南充市社科研究“十 三五”规划2020年度项目: 《乡村振兴过程中文化铸 魂的现代意蕴与路径研究》（NC2020B101）的阶段 性成果之一。

\section{REFERENCES}

[1] Song Xiaoxia, Wang Tingting. Cultural Revitalization is the "root" and "soul" of Rural Revitalization-The Importance Analysis, Current Situation and Countermeasures of Rural Cultural Revitalization. Shangdong Social Sciences, Vol.4, 2019, pp.176-181.

[2] Zhang Liming.The Cultural Dimension of Casting Soul to Educate People. Ideological and Political Education Research,Vol.6, 2020, pp.137-141.

[3] Xi Jinping. Achieving a Decisive Victory in Building a Moderately Prosperous Society in All Respects to the Great Victory of Socialism with 
Chinese Characteristics for a New Era. The People's Daily, 2017-10-19 (1).

[4] Luo Yuting. The Cultural-soft-power Strategy in the New Era. Studies on Cultural Soft Power, Vol.6, 2018, pp.33-41.

[5] Xi Jinping. Speech at the Forum of Peking University. The People's Daily, 2018-5-3 (2) .

[6] Xi Jinping. The Governance of China (Volume II). Beijing: Foreign Languages Press, 2017, p349.

[7] Li Zhongjun. Analysis on the Problems of Casting Soul and Educating People in Contemporary China. Social Science Front, Vol. 6, 2016, pp.1-8.

[8] Xie Ru. Cultural Construction for Rural Revitalization and Shape Casting Soul. Magazine of the Chinese People's Political Consultative Conference, Vol. 20, 2020, pp.36-37. 